DOI: $10.30973 /$ esdi/2018.4.1/4

ISSN: $2448-4857$

Volumen 4 | Número 1

marzo 2018 | agosto 2018

pp. 36-50

\title{
El èthos: entre el kairós y las formaciones discursivas
}

\author{
María Alejandra Vitale \\ Universidad de Buenos Aires \\ vitaleale@hotmail.com
}

\begin{abstract}
Resumen
El artículo plantea que en el estudio del èthos o imagen de sí que el orador construye en su discurso se involucran dos nociones de diversa tradición. Una noción, que proviene de la retórica, es la de kairós; otra, usada en la perspectiva francesa de análisis del discurso, es la de formación discursiva. El trabajo analiza discursos de la expresidente argentina Cristina Fernández de Kirchner, en los que se identifica, por un lado, un èthos pedagógico y experto, vinculado con el kairós y el aquí y ahora de la enunciación, y, por otra parte, un èthos guerrero y anti institucionalista, ligado interdiscursivamente a una formación discursiva propia a una ideología populista.
\end{abstract}

Palabras clave: éthos, kairós, formación discursiva, interdiscurso, Cristina Fernández de Kirchner

\begin{abstract}
This paper argues that in the study of the èthos or self-image built by the orator in his/her discourse two notions of diverse tradition are involved. One, that comes from rhetoric, is the notion of kairós; the other, used in the french school of discourse analysis, is discoursive formation. This article illustrates its argument with discourses from Argentina's former President Cristina Fernández de Kirchner. In her speech I identify, on the one side, a pedagogic and expert èthos, related to the kairós, and the enunciation's here and now. On the other side, I find a warrior and anti-institutionalist èthos, linked interdiscoursively to a discoursive formation typical of a populist ideology.
\end{abstract}

Keywords: éthos, kairós, discoursive formation, interdiscourse, Cristina Fernández de Kirchner

Fecha de recepción: 25 de noviembre de 2017 | Fecha de aceptación: 28 de enero de 2018 
$\mathrm{E}$ n los Estudios del Discurso de tendencia francesa se observa, desde la década de los ochenta del siglo pasado (Maingueneau, Nouvelles tendances), un creciente interés en la noción retórica de èthos (Amossy, Images de soi, La présentation de soi, "L' éthos"; Maingueneau, "Problèmes", "Retour"). ${ }^{1}$ El foco en esta noción está especialmente motivado en el auge de la lingüística del discurso, basada en la teoría de la enunciación, que tiene como objeto de estudio la subjetividad en el lenguaje (Amossy, Images de soi). Este peso de la lingüística del discurso ha sido calificado por Adam como una "retorización de la lingüística", que consiste en la descripción lingüística de fenómenos sobre los cuales trataba la Retórica, entre los que se ubica el èthos.

En relación con ello, el propósito de este trabajo es reflexionar sobre dos dimensiones que considero atraviesan la problemática del èthos; una, vinculada con una noción clave de la retórica, el kairós, y otra, relacionada con una noción fundamental en el análisis del discurso, la de formación discursiva.

A continuación, me refiero a estas dos dimensiones involucradas en el èthos, luego, ilustro con discursos de la expresidente argentina Cristina Fernández de Kirchner, y finalizo con las conclusiones.

\section{Èthos y kairós}

Es probable que Gorgias haya sido el primero en introducir la noción de kairós en el campo de la retórica. El kairós consiste en "transformar el valor de los hechos en el sentido en que exigen el público y las circunstancias" (Woerther 234). ${ }^{2}$ Se trata de un arte de improvisar que puede ser definido como lo que conviene en tal tiempo, en tal lugar, en tal situación. ${ }^{3}$ Al respecto, Meyer afirma:

\footnotetext{
${ }^{1}$ La tendencia anglosajona denominada Análisis Crítico del Discurso (ACD) ha retomado también esta temática, específicamente en el caso de Norman Fairclough. Para un comentario sobre los modos en que Fairclough retoma las propuestas de Maingueneau sobre el èthos, ver Vitale.

${ }^{2}$ Las traducciones del francés son mías.

${ }^{3}$ Por ello Pernot asocia la noción de kairós de los sofistas con su visión relativista del mundo: no existen una verdad y una justicia definidas de una vez para siempre, a las que debería conformarse
} 
Para Gorgias, el kairós hace referencias a un punto fundamental: el que concierne a la articulación de los objetivos del orador con el tiempo, el lugar y las circunstancias del auditorio al que se dirige, dentro de un proceso que tiene como objetivo la producción de un discurso conveniente (prepô), es decir, que combine con armonía la expresión y el tema, la forma y el contenido. (Histoire 25)

La valoración del kairós implica que la eficacia del discurso reside esencialmente en la facultad, propia del orador, de saber el momento propicio para tomar la palabra y la manera en que debe presentar la materia sobre la que versa el discurso. Ello exige ciertas cualidades en el orador, por eso para Isócrates el kairós depende de la perspicacia y de la prudencia de quien habla. Como sostiene Woerther, el kairós remite en Isócrates a la phronêsis, la prudencia como una de las virtudes que componen el èthos para Aristóteles - la imagen que el orador construye de sí en su discurso, complejo tripartido formado por la phronêsis (prudencia), la areté (virtud moral) y la eunioia (benevolencia). ${ }^{4}$

A su vez, Woerther hace hincapié en que la prudencia en la Retórica de Aristóteles consiste en adaptarse al auditorio, lo que pasa por un conocimiento objetivo de los regímenes políticos, dado que el auditorio era aprehendido como un cuerpo político. En este sentido, la prudencia como virtud propia del èthos es definida por Aristóteles como un saber oportuno y eficaz, lo que liga la prudencia a la noción de kairós de la tradición preplatónica. Ėthos y kairós, de esta manera, se remiten uno al otro mutuamente.

El èthos, tal como lo entiende Aristóteles en la Retórica, gracias a la prudencia vinculada con el kairós que le es inherente, está relacionado a la producción del discurso en función de la ocasión. El èthos atravesado por el kairós atañe así a la singularidad de una situación retórica específica, al aquí y ahora de una enunciación, lo que desde el análisis del discurso puede ser pensado con la noción de acontecimiento discursivo. ${ }^{5}$

el discurso, sino que, por el contrario, se construyen al instante a través del discurso que las hace existir.

${ }^{4}$ Sobre este complejo tripartito, ver Walzer, Tiffany y Gross.

${ }^{5}$ En un trabajo clásico, Courtine vincula la noción de acontecimiento discursivo con las nociones de formulación, intradiscurso, dominio de actualidad, enunciación y sujeto enunciador. La memoria discursiva, es decir, el retorno, reformulación u olvido — en la actualidad de un acon- 
Específicamente en el campo del discurso político, Philippe-Joseph Salazar revisita la distinción entre las dos palabras del griego antiguo, èthos con una inicial eta $(\tilde{\eta})$ y èthos con una inicial epsilon ( $(\varepsilon)$. Estas dos palabras son diferenciadas por un acento en transliteración, pero esta diferencia es una tensión fundamental: una designa el carácter individual, el temperamento, la moral del orador (èthos con eta inicial), y otra se refiere a las costumbres, el hábito social y la norma de comportamiento del grupo (èthos con epsilon). Salazar advierte que el carácter del político tiene que ser acorde a las costumbres de su auditorio y que la fabricación del acuerdo entre estos dos èthos debe ser la adecuada en función de la eficacia del discurso.

\section{Ėthos y formación discursiva}

Cuando Maingueneau (Nouvelles tendances) se interesaba más en las cuestiones ideológicas, pensó el èthos en relación con las formaciones discursivas. En efecto, hizo hincapié en que el análisis del discurso no puede integrar la problemática del èthos si no rechaza toda concepción psicologizante y voluntarista del sujeto involucrada en la concepción retórica, según la cual, el orador, como un actor, representaría el papel de su elección en función de los efectos que quiere producir sobre su auditorio. En realidad, desde el punto de vista del análisis del discurso, tanto ese papel como esos efectos son impuestos por una formación discursiva, que constituye el aspecto material de la ideología. La noción de formación discursiva, pensada — se sabeprimero por Michel Foucault y reelaborada luego por Michel Pêcheux, designa el conjunto de reglas constructoras de discursos que determinan lo que puede o no ser dicho por un sujeto, que no es la fuente del sentido de sus enunciados sino que se constituye como tal al identificarse con determinada posición de subjetividad delimitada por esa formación discursiva. Se trata, en suma, de una relectura de la noción

tecimiento discursivo- de lo ya dicho, es articulada con las nociones de interdiscurso, dominio de memoria, enunciado y sujeto de saber de una formación discursiva. Ver también la entrada "acontecimiento discursivo" en Charaudeau y Maingueneau. 
de èthos desde la concepción de sujeto de la teoría althusseriana de la ideología a la que se adhirió Maingueneau en una etapa anterior a su actual producción.

Para Maingueneau, el èthos, tanto de un texto escrito como oral, incluye un tono - por ejemplo, moderado, jovial o agresivo - y un carácter, considerado como un haz de rasgos psicológicos estereotipados. Asimismo, el èthos integra la representación estereotipada construida en el discurso del cuerpo del enunciador, no sólo en el sentido de una complexión física, sino también un modo de vestirse y de habitar el espacio social. A partir del planteamiento de que el èthos incluye el cuerpo del enunciador, Maingueneau introdujo la noción de incorporación para dar cuenta de tres fenómenos estrechamente articulados:

- Una formación discursiva le da una "corporalidad" a la figura del enunciador y, correlativamente, a la del destinatario, ella les "da cuerpo" textualmente;

- esta corporalidad permite la "incorporación" por los sujetos de esquemas que definen una manera específica de habitar el mundo y el espacio social;

- esos dos primeros aspectos son una condición de la "incorporación" imaginaria de los destinatarios al grupo, al cuerpo, de los adeptos del discurso.

De este modo, Maingueneau piensa la eficacia del discurso como identificación del auditorio con una manera de ser y de habitar el mundo ligadas indisociablemente a una manera de decir y de enunciar del orador. Este mecanismo es el que permite explicar el sometimiento ideológico como la identificación con una posición de subjetividad inherente a una determinada formación discursiva.

En tanto tal, una formación discursiva implica un sujeto de saber como posición de subjetividad, se vincula con la noción de estructura e interdiscurso y con el eje de la repetición, de la regularidad. El acontecimiento discursivo, con el que está ligado el èthos a partir de la noción de kairós, en cambio, se relaciona con las nociones de intradiscurso, enunciación y sujeto enunciador.

La construcción de todo èthos, en suma, estaría atravesada por una tensión entre su relación con el kairós, con una situación de enunciación específica, una singularidad, por un lado, y con una formación discursiva, el interdiscurso y la repetición, por el otro. 
María Alejandra Vitale

\section{Kairós y formación discursiva en el èthos de Cristina Fernández de Kirchner}

A continuación, ilustraré estas consideraciones con los dos discursos de asunción de la expresidente argentina Cristina Fernández de Kirchner, que fueron pronunciados, respectivamente, el 10 de diciembre de 2007 y de 2011.

La situación retórica, la singularidad de la situación de enunciación de estos dos discursos, tuvo sus peculiaridades. Cristina Fernández de Kirchner asumió la presidencia luego de un período de cuatro años en el que su marido, Néstor Kirchner, se había desempeñado como presidente, desde 2003 a 2007. ${ }^{6}$ Ella fue elegida candidata no mediante elecciones internas, sino por la voluntad de Néstor Kirchner, lo cual aumentaba el desafío de que demostrara que estaba a la altura de desempeñarse como primera mandataria. Su trayectoria como diputada y senadora justicialista, y su destacado papel como opositora al (segundo) gobierno neoliberal de Carlos Menem, ${ }^{7}$ incidían a favor de que contara con una imagen previa positiva. Sin embargo, el alto índice de popularidad que seguía teniendo Néstor Kirchner, ${ }^{8}$ la preferencia de parte de la población y del aparato del partido justicialista a favor de que él hubiese sido el candidato presidencial, y la sospecha de que la candidatura de Cristina Fernández de Kirchner expresaba el proyecto oculto de que con Néstor Kirchner intentarían traspasarse indefinidamente la presidencia (Aboy Carlés), eran factores negativos que podían perjudicar su imagen previa al discurso de asunción de 2007. Por otra parte, a la vez que debía mostrarse como continuadora de la gestión de Néstor Kirchner, tenía que diferenciarse de ésta para construir una identidad propia.

\footnotetext{
${ }^{6}$ Néstor Kirchner (1950-2010) fue presidente de Argentina de 2003 a 2007. En 2003, accedió a la presidencia encabezando el Frente para la Victoria, nombre de una alianza electoral integrada, entre otros, por sectores del Partido Justicialista (PJ) y de la Unión Cívica Radical (UCR), el Partido Comunista (PC) y el Partido Humanista (PH). Dicha alianza presentó la fórmula Cristina KirchnerJulio Cobos (proveniente de la UCR) para las elecciones presidenciales de 2007 y la fórmula Cristina Kirchner-Amado Boudou para las elecciones presidenciales de 2011.

${ }^{7}$ Carlos Saúl Menem se desempeñó como presidente durante dos periodos consecutivos: 19891995 y $1995-1999$.

${ }^{8}$ Sobre la popularidad de Néstor Kirchner y el proceso electoral de 2007, ver Gallo.
} 
En su segundo discurso de asunción, el desafío radicaba en que Néstor Kirchner había muerto - falleció el 27 de octubre de 2010- y la presidente reelecta debía demostrar que podría gobernar sin el asesoramiento permanente de su marido. Por otra parte, la tensión que desde la muerte de este se había generado con el líder de la Confederación General del Trabajo, Hugo Moyano, dejaría también sus huellas en su discurso de 2011.

En relación con estas situaciones retóricas, Cristina Fernández de Kirchner construye de sí misma la imagen de una política competente y experimentada que transmite sus saberes al auditorio y configura un èthos que denomino pedagógico-experto. Este éthos remite a una escena de habla en la que Cristina Fernández de Kirchner ocupa el lugar de una profesora que da clases a sus alumnos, de allí que emplee procedimientos característicos del discurso explicativo (Zamudio \& Atorresi), orientados a facilitar la comprensión por parte de los destinatarios.

En su primer discurso de asunción, dije, Cristina Fernández de Kirchner tiene que comunicar que tiene el nivel y la autoridad para ocupar la primera magistratura de la Argentina; en el caso de su segundo discurso de asunción, el desafío radica en persuadir de que podrá gobernar sola, sin el acompañamiento de Néstor Kirchner. En relación a estos desafíos, Cristina Fernández de Kirchner da de sí la imagen de una política que posee sólidos conocimientos sobre economía, lo que se construye mediante el empleo de terminología técnica como "modelo económico con matriz diversificada", "imbalances mundiales" o "spread de diferencias". Para facilitar la rápida comprensión de una noción, la presidente argentina utiliza el recurso explicativo que consiste en la paráfrasis intradiscursiva (Zamudio \& Atorresi 75), como cuando en su discurso de 2011 formula "la productividad de las empresas, esto es el Producto Bruto Interno dividido por cada uno de los trabajadores". Al mismo tiempo, la imagen de experta en economía se acrecienta con la apelación a indicadores estadísticos como elementos de prueba (Cussó \& Gobin), por ejemplo:

En el año 1980, la relación entre el producto bruto global, todo lo que produce el mundo en bienes y servicios, y el stock de activos financieros, llámese bonos, derivados, lo que fuere, era del 1,1. En el año 2010, llegó a 3,4 habiendo tenido 
una punta en el 2006 de 3,6 veces. ¿Qué significa esto? Algo muy simple: el dinero, que es el elemento fungible por esencia para comprar bienes y servicios, hay casi 4 veces más dinero que bienes y servicios para comprar.

En la cita se observa que Cristina Fernández de Kirchner emplea preguntas polifónicas que Oswald Ducrot denomina didácticas porque el locutor expresa el punto de vista de su auditorio que no sabe la respuesta, conocida por el locutor, como cuando ella pregunta luego de referirse al aumento del stock de activos financieros “¿Qué significa esto?”, para pasar a explicar ese significado.

Se construye una imagen de sí de profesora, también, a través de actos de habla manifestados en los verbos realizativos explícitos "reflexionar", "corregir" y "recomendar". En efecto, Cristina Fernández de Kirchner, en el discurso de 2007, afirma: "quiero en esta tarde y en este lugar en el que estuve tantos años reflexionar con ustedes", con lo que genera la imagen de una política en cuyo discurso el logos es protagonista. En la alocución de 2011, al referirse a una reunión pasada que compartió con el titular de la Unión Industrial Argentina en la que éste expresó una opinión, la presidente aclara "yo lo corregi", posicionándose en el lugar de quien tiene la verdad y advierte el error de otro. Ese lugar del saber y de poder se observa también en ese mismo discurso, cuando Cristina Kirchner formula el acto de habla "recomendar": "recomiendo, no se guíen por la letras de molde, guíense por la mirada de la gente".

El èthos pedagógico-experto y la imagen de sí de profesora se vinculan con la formulación de negaciones, ${ }^{9}$ que funcionan frecuentemente como corrección de las palabras de otros. Por ejemplo, en el discurso de 2011, la presidente argentina sostuvo: “También la competitividad exigirá que examinemos en forma conjunta utilidades y rentabilidades para hacerlas acorde con los estándares internacionales. Esto no significa, como se dijo por ahí, ninguna ley”. Esta forma de negación, conocida como metalingüística, ${ }^{10}$ construye una imagen de sí de quien privilegia su

\footnotetext{
${ }^{9}$ Para un estudio de las negaciones en el discurso electoral de 2007 de Cristina Fernández de Kirchner, ver Maizels.

${ }^{10}$ Según García Negroni, la negación metalingüística, que opone dos locutores diferentes o un mismo locutor en momentos diferentes, siempre es descalificadora de un marco de discurso previo y tiene la función fundamental de instaurar un nuevo espacio de discurso, presentado por el locutor como el único adecuado para la caracterización argumentativa de la situación de la que habla.
} 
propio punto de vista frente al que sostienen las palabras negadas de otro, en este caso no identificado explícitamente gracias al uso de la forma cuasirrefleja impersonal "se". Al negar, la oradora corrige la palabra de ese otro y es a partir de este movimiento que queda identificada con el conocimiento verdadero, en una posición asimétrica superior frente a quien es corregido y frente a su propio auditorio.

Por otra parte, en su primer discurso de asunción afirma "Mi generación de eso puede dar cátedra" y en su segundo discurso sostiene "debemos aprender la lección". Los argentinos quedan así ubicados en el lugar de sujeto del aprendizaje en tanto que Cristina Fernández de Kirchner se posiciona como la profesora que les transmitirá sus saberes y cuyo poder se manifiesta en la modalidad deóntica ("debemos"). El sintagma metafórico "los peores alumnos del grado", asimismo, utilizado en el discurso de 2011 para representar a los argentinos luego del default de 2001, ratifica la construcción de la imagen de profesora.

La legitimación por el saber y la experiencia inherentes al èthos pedagógico-experto se fabrican también mediante el recuerdo de su pasado de diputada y senadora; por ejemplo, la presidente afirma en su discurso de 2007: "Yo he pertenecido durante 12 años a este Parlamento". En este primer discurso de asunción, la primera persona del plural oscila entre una referencia máxima (yo + ustedes + ellos), que corresponde a un nosotros inclusivo con referencia "nosotros, los argentinos", y un nosotros exclusivo que tiene como referencia - en los casos en que la nueva presidente recuerda su pasado parlamentario- a "nosotros, los diputados" (yo + ellos), y a "nosotros, los kirchneristas" (yo + Néstor Kirchner y su gobierno), que le permite capitalizar a su favor lo que presenta como éxitos del gobierno de su marido, que es en ese momento el presidente saliente: "las cosas que hemos hecho en estos cuatro años y medio que han sido tan importantes". En el segundo discurso de asunción, en cambio, la primera persona del plural oscila entre el "nosotros, los argentinos" y el "nosotros, los de mi gobierno", que tiende a legitimar a Cristina Fernández de Kirchner mediante la enumeración de los que presenta como logros de su período presidencial anterior: "hemos podido generar más de cinco millones de puestos de trabajo".

Pensado el èthos desde la noción de formación discursiva, en los discursos de asunción de Cristina Fernández de Kirchner se puede identificar una posición de subjetividad a la que le son inherentes ciertos rasgos discursivos que la expresi- 
María Alejandra Vitale

dente argentina comparte con el expresidente de Venezuela Hugo Chávez y que están mucho más marcados en su segundo discurso de asunción. En efecto, esta posición de subjetividad se corresponde con una ideología que cuestiona el institucionalismo, la gestión demoliberal de poder y que se enfrenta a la concepción de la política como regulación del conflicto. Ante esta concepción liberal de la política, dicha posición de subjetividad va en contra de lo institucional y adhiere a lo político como antagonismo amigo-enemigo (Schmitt).

Esta posición de subjetividad antiinstitucionalista se manifiesta en los discursos de asunción en la ruptura de las convenciones propias de este género de la retórica presidencial. En efecto, los discursos de asunción tienden a dar unidad al pueblo, a construir a la audiencia como comunidad nacional, afirmando valores que la unen y evitando la polémica; además, apelan a la memoria nacional (aunque siempre con un énfasis selectivo) $y$, a diferencia del discurso de campaña, no se refieren a la historia personal del presidente (Campbell \& Jamieson).

Cristina Fernández de Kirchner evoca un tramo de la historia reciente argentina sobre el que no hay pleno consenso, dado que si bien desde la transición democrática se construyó una hegemonía discursiva (Angenot) que condena la última dictadura militar y el terrorismo de Estado responsable de los desaparecidos, no sucede lo mismo respecto de la lucha armada practicada por jóvenes militantes de la década de los setenta. Sin embargo, la presidente argentina en su discurso de 2007 se integra con Néstor Kirchner en la generación revolucionaria de los setenta diciendo: "somos miembros de una generación que creyó en ideales y en convicciones". En la apertura de su discurso de 2011, se ubica implícitamente en el lugar de una joven desaparecida durante la última dictadura militar cuyo nombre - informa - le fue puesto a un asteroide por pedido de la Universidad de la Plata a la Unión Astronómica Mundial. En efecto, Cristina Fernández de Kirchner sostiene: "esta joven podría haber estado sentada en este mismo lugar en donde estoy sentada yo". Al decir esto, se construye como una militante revolucionaria de los setenta y, a continuación, se compara implícitamente con Dilma Rousseff, la expresidente de Brasil, tal como aparece de joven en una foto que circuló en la prensa argentina donde se la ve sentada frente a un tribunal militar. 
Otra característica rupturista de los dos discursos de asunción de Cristina Fernández de Kirchner es su alta dimensión polémica. En efecto, la expresidente argentina se enfrenta con el alfonsinismo, porque detuvo los juicios a los militares represores, los empresarios que sólo buscan rentabilidad, los medios de comunicación que la critican, la política económica de los países europeos y el gobierno de Fernando de la Rúa. En la alocución de 2011, se enfrenta también, sin nombrarlo, con Hugo Moyano, el líder de la Confederación General del Trabajo, con quien luego profundizó su distanciamiento. En relación con esta alta dimensión polémica, en particular el discurso de 2007 utiliza la metáfora estructural (Lakoff y Jhonson) de que la política es una guerra, que se manifiesta en lexemas como "batalla", "victoria" y "lucha", lo que contribuye a crear un èthos que se puede calificar de guerrero. El uso de la metáfora estructural "la política es una guerra" es un rasgo compartido con el discurso político de Hugo Chávez, que ha sido estudiado por la investigadora venezolana Irma Chumaceiro.

Otro rasgo discursivo que rompe las convenciones que rigen el género discurso de asunción y que asemejan mucho el discurso de Cristina Fernández de Kirchner con el de Hugo Chávez es la incorporación de interpelaciones a miembros de su gobierno que están delante de ella como parte del auditorio y que introducen esbozos de conversaciones. De esta manera, Cristina Fernández de Kirchner se dirige directamente a políticos de su partido presentes ante ella y les dice: “Calcagno, ¿dónde estás?” o “iJulián, qué cosa!”, generando una escena de habla que se puede calificar de diálogo entre amigos. De modo similar, Hugo Chávez, por ejemplo, en su discurso de asunción de 1999, sostuvo: "Hoy Venezuela está así, en una situación, doctor Velázquez, usted que conoce mucho más que yo la historia...." 11

Asimismo, otro rasgo rupturista de las convenciones genéricas del discurso de asunción es la introducción de escenas privadas de la presidente asociadas a la vida cotidiana. Por ejemplo, Cristina Fernández de Kirchner al principio de su segundo

\footnotetext{
${ }^{11}$ Este rasgo discursivo está vinculado a lo que Norman Fairclough denomina conversacionalización del discurso público. Para un análisis detallado en los discursos de asunción de Cristina Fernández de Kirchner ver Vitale.
} 
discurso recuerda: "Cuando hoy me levanté como todas las mañanas y leí los diarios.... De modo semejante, Hugo Chávez, en su discurso de asunción de 1999, recuerda: "Me decía un grupo de amigos hace unas noches atrás...”.

Por último, la violación de las convenciones inherentes al acto de habla juramento, que implica la enunciación de una fórmula prefijada, es compartida por el segundo discurso de asunción de Cristina Fernández Kirchner con los discursos de asunción de Hugo Chávez de 1999 y de 2007. Así, ella juró en 2011 "Por Dios, la Patria y por Él", sintagma donde el pronombre "Él” se refiere a Néstor Kirchner, construyéndolo como la encarnación de Dios y de la Patria. Chávez, en 2007 había afirmado: "Juro delante de Dios, juro delante de la Patria, juro delante de mi pueblo, que esta moribunda Constitución haré cumplir...", cuando la fórmula era sólo "ante Dios y ante la Patria" y cerró su discurso de asunción de 2007 con la sentencia: "Patria y socialismo o muerte. Lo juro", que — entre otras palabras que dijono respetaba la fórmula del juramento.

\section{Conclusiones}

Volviendo a las consideraciones realizadas al principio de este trabajo, planteo que es posible pensar la construcción del èthos en la tensión entre el kairós, la singularidad de una situación retórica y un acontecimiento discursivo, por un lado, y la repetición interdiscursiva inherente a una posición de subjetividad propia a una formación discursiva, por el otro. Esto se observa en que, ante las exigencias de las situaciones retóricas en las que Cristina Fernández de Kirchner tiene que demostrar que está a la altura de ser presidente de Argentina, construye un èthos que califico de pedagógico-experto. A la vez, como posición de subjetividad de una formación discursiva antiinstitucionalista propia de una ideología que en términos de Ernesto Laclau se puede llamar populista, construye un èthos guerrero y rupturista que también se manifiesta en los discursos de asunción de Hugo Chávez. En este sentido, el èthos es concebido como una de las dimensiones de las formaciones discursivas. 
María Alejandra Vitale (vitaleale@hotmail.com)

Doctora en Lingüística de la Universidad de Buenos Aires, donde se desempeña como investigadora del Instituto de Lingüística y como profesora titular. Obtuvo el Posdoctorado en Estudios Lingüísticos en la Facultad de Letras de la Universidad Federal de Minas Gerais, Brasil. En la actualidad, es presidente de la Organización Iberoamericana de Retórica (OIR) y directora de la revista electrónica Rétor, de la Asociación Argentina de Retórica (AAR).

\section{Obras Citadas}

Aboy Carlés, Gerardo. "El declive del kirchnerismo y las mutaciones del peronismo", Nueva Sociedad 249 (2014): 4-15.

Adam, Jean-Michel. "De la grammaticalizacion de la rhétorique à la rhétorisation de la linguistique. Aide-mémoire”. Koren, R. y Amossy, R. (eds.). Après Perelman. Quelles politiques pour les nouvelles rhétoriques? L'argumentation dans les sciences du langage. París: L'Harmattan, 2002: 23-55.

Amossy, Ruth (Dir.) Images de soi dans le discours. La construction de lethos. París: Delachaux et Niestlé, 1999.

Amossy, Ruth. La présentation de soi. Ethos et identité verbale. París: PUF, 2010.

Amossy, Ruth. "Léthos et ses doubles contemporains. Perspectives disciplinaires", Langage \& Societé 149 (2014): 13-30.

Angenot, Marc. El discurso social. Los límites de lo pensable y lo decible. Buenos Aires: Siglo XXI, 2010.

Aristóteles. Retórica. Quintín Racinero (int., trad. y not.). Madrid: Gredos, 1990.

Campbell, Karlyn Kohrs \& Kathleen Hall Jamieson. Presidents creating the presidency. Deeds done in words. Chicago: The University of Chicago Press, 2008.

Chumaceiro, Irma. "Las metáforas políticas en el discurso de dos líderes venezolanos: Hugo Chávez y Enrique Mendoza”, revista ALED 4.2 (2004): 91-113. 
Courtine, Jean-Jacques. "Analyse du discours politique (le discours communiste adressé aux chrétiens)", Langages 62 (1981): 9-128.

Charaudeau, Patrick y Dominique Maingueneau. Dictionnaire d'analyse du discours. París: Le Seuil, 2002.

Cussó, Roger \& Corinne Gobin. "Du discours politique au discours expert: le changement politique mis hors débat?” Mots. Les langages du politique 88 (2008): 5-11.

Ducrot, Oswald. El decir y lo dicho. Buenos Aires: Hachette. 1984.

Foucault, Michel. L archéologie du savoir. París: Gallimard. 1969.

García Negroni, María Marta. "La negación metalingüística: argumentación, gradualidad y reinterpretación”, Signo y Seña 9 (1998): 227-252.

Gallo, Adriana. "Reelección inmediata y sucesión en clave matrimonial. Análisis del recambio presidencial argentino de 2007”, Espacios públicos 11. 23 (2008): 168-199.

Maingueneau, Dominique. Nouvelles tendances en analyse du discours. París: Hachette, 1987.

Maingueneau, Dominique. "Problèmes d'ethos", Pratiques 113-114 (2002): 55-67.

Maingueneau, Dominique. "Retour critique sur l'éthos", Langage et Societé 149 (2014): 31-48.

Maizels, Ana Laura. “Negación, otras voces’ y ethos. Un análisis de los discursos de campaña política de Cristina Fernández de Kirchner", RILL 17.1-2 (2007): 1-11.

Meyer, Michel, dir. Histoire de la rhétorique des Grecs à nos jours. París: Librairie Générale Française, 1999.

Laclau, Ernesto. La razón populista. Buenos Aires: Fondo de Cultura Económica, 2005 .

Lakoff, George y Mark Johnson. Metáforas de la vida cotidiana. Madrid: Cátedra, 1995.

Pêcheux, Michel. Les vérités de la Palice. París: Hachette, 1975. 
Pernot, Laurent. La Rhétorique dans l’Antiquité. París: Librairie Générale Française, 2000.

Salazar, Philippe-Joseph. L’hyperpolitique. Une passion française. París: Klincksieck, 2009.

Schmitt, Carl. El concepto de lo político. Madrid: Alianza Editorial, 1991.

Vitale, María Alejandra. "El ethos en la 'conversacionalización' del discurso público. Las alocuciones de asunción de la presidente argentina Cristina Fernández de Kirchner". Langage et Societé 149 (2014): 49-67.

Walzer, Arthur E., Michael Tiffany y Alan G. Gross. "Aristotle's Rhetoric: a guide to the scholarship", en Gross, Alan and Arthur. E. Walzer, Rereading Aristotle' Rhetoric. Carbondale: Sothern Illinois University Press, 2008. 185-203.

Woerther, Frédérique. Lèthos aristotélicien. Genèse d’une notion rhétorique. París: Vrin, 2017.

Zamudio, Bertha \& Ana Atorresi. La explicación. Buenos Aires: EudebA, 2000. 